\title{
Community Smart Grid Utilizing Dynamic Demand Response and Tidal Power for Grid Stabilization
}

\author{
Anna Demeo ${ }^{1,2^{*}}$, Michael L. Peterson ${ }^{2}$ \\ ${ }^{1}$ College of the Atlantic, Bar Harbor, USA; ${ }^{2}$ Department of Mechanical Engineering, University of Maine, Orono, USA. \\ Email:*ademeo@coa.edu
}

Received July $15^{\text {th }}, 2013$; revised August $15^{\text {th }}, 2013$; accepted August 22 $2^{\text {nd }}, 2013$

Copyright (C) 2013 Anna Demeo, Michael L. Peterson. This is an open access article distributed under the Creative Commons Attribution License, which permits unrestricted use, distribution, and reproduction in any medium, provided the original work is properly cited.

\begin{abstract}
Conventional electricity generation is one of the largest contributors to climate change. Renewable energy sources are a promising part of the solution but uncertainty combined with a lack of controllability prevents renewable sources of power from being direct substitutes of conventional energy sources. This shift towards a higher penetration of renewable energy into the electric grid can be realized with the implementation of a more sophisticated smart grid, which uses dynamic demand response to alter demand on following generation. Research on renewable energy penetration of the grid predominately focuses on wind and solar power resources but demand cannot always match availability from these sources and therefore greatly increases the need for energy storage. Tidal power differs from solar and wind. It's a predictably renewable resource which makes it extremely valuable even on a relatively small scale. Introduction of tidal power in a high penetration micro-grid can serve to stabilize the grid and reduce the amount of storage required. Widely different time scale for wind, solar and tidal power availability results in low cross correlations and therefore increases stability. This research describes an incremental approach to migrating a grid-tie island towards the formation of a smart-micro grid. The system will include a high penetration of three distributed generation systems, wind, solar and tidal and utilize commercially available energy storage and a smart-home management controller. Dynamic demand response through load balancing is implemented to minimize interactions with the electric grid. A second component of this work is to determine the optimum tidal generation capacity for the micro grid such that needed storage capacity from batteries or the utility grid is minimized.
\end{abstract}

Keywords: Smart Grid; Tidal Power; Renewable Energy; Micro Grid

\section{Introduction}

Integrating renewable energy into the electric grid is a promising area of research in the widespread effort to address climate change. Conventional electricity generation is one of the largest contributors to climate change due to the production of greenhouse gasses [1]. Renewable energy sources cannot be directly substituted for conventional energy sources due to their uncontrollable and intermittent nature [2]. The conventional electricity grid functions on a generation following load principle, which entails controlling power plants to match varying power consumption [3]. Incorporating a higher penetration of renewable energy sources into the grid will require a paradigm shift to a load following generation model in which demand side management actively controls loads to off-

\footnotetext{
${ }^{*}$ Corresponding author.
}

set variations in power production. This shift can only be realized with implementation of a more sophisticated electric grid.

Smart-grid is an umbrella term used to describe the technological upgrade of the grid or micro-grids to significantly increase penetration of renewable energy sources [4]. A smart-grid will dynamically monitor and control demand based on power production and consumption, known as dynamic demand response (DDR) [5]. Load balancing capacity, which is the available amount of dispatchable loads for DDR, grid energy storage and distributed renewable generation are the key components of a smart micro grid. Benefits of a smart-grid include increased penetration of renewable sources of power and an overall reduction in power consumption on the consumer side, which ultimately increases efficiency and grid security, lowers cost, and reduces carbon emissions. 
Uncertainty combined with a lack of controllability prevents renewable sources of power from being direct substitutes for conventional energy sources. Research on renewable energy penetration of the grid predominately focuses on wind and solar power resources and the associated need to control demand through a smart grid network [6]. In addition to the inability to precisely characterize wind and solar power production, the reality that demand cannot always match availability from these sources greatly increases the need for energy storage.

Tidal power differs from solar and wind in that it is a predictable renewable resource. Although typically tidal sites do not offer as large of a supply as offshore wind [7], the predictability of the resource is extremely valuable as the introduction of tidal power, for small, geographically appropriate micro-grids, into a high penetration micro-grid can serve to stabilize the grid and reduce the amount of storage required. By further aggregating renewable power generation and providing a predictable input, variability and uncertainty are also reduced. Widely different time scale for wind, solar and tidal power availability results in low cross correlations and therefore increases stability.

Island communities may be able to most immediately benefit from the development of smart micro-grids with predominately renewable energy penetration. Both gridtie and autonomous islands experience high and fluctuating energy costs due to losses from underwater power cables in the first instance and fuel purchase and transportation costs for generators in the latter. These costs are a strong incentive for island communities to integrate local energy sources. Geographically islands tend to provide an opportunity for a variety of renewable power sources including wind, tidal, wave and solar production. Moreover, many island communities operate at a scale that is suitable for smart-grid development with commercially available storage and smart-home technology.

This paper describes an incremental approach to migrating a grid-tie island towards the formation of a smartmicro grid. The system will include a high penetration of three distributed generation systems, utilize commercially available energy storage and a smart-home management controller. The primary objectives of this paper are to:

1. Determine optimum tidal generation capacity based on demand-supply balance of energy consumption and solar and wind power generation. Utilize tidal power for grid stabilization such that needed storage capacity from batteries or the utility grid is minimized.

2. Detail a non-autonomous smart-grid configuration using off the shelf storage and control equipment and off the shelf home automation management software to implement dynamic load balancing to minimize interaction with the utility grid. This will result in reduced power loss in the underwater cable, lower costs and increased efficiency. Utilize this non-autonomous smart micro-grid to aid in the refinement of an autonomous solution through monitoring of real-time power magnitude and direction at the utility grid source.

\section{Site}

Roque Island is a privately owned, 1300-acre island off the coast of Maine. Fifteen acres of cleared land on the southeast shore hosts six homes and a small, year round farm comprised of two large barns and several out buildings for horses and livestock for food production six staff members live year round on the island in three of the houses. The remaining three houses are occupied from May through October by members of the family trust that owns the island. Population of the island averages $30 \mathrm{du}-$ ring the peak usage months of July, August and September. Average energy use for the island is $38 \mathrm{MWh}$ per year. The island is connected to the mainland grid through an $1800 \mathrm{~m}$ underwater power cable. The primary energy consumption on the farm is from the water pumping system and heating and refrigeration in the main farmhouse. The water is pumped to a central cistern then piped throughout the island. The farmhouse is 7655 square feet with an attached greenhouse. In addition to housing seasonal workers and being the main gathering place with a large communal kitchen, the farmhouse holds multiple freezers and a walk in refrigerator for food storage. Figure 1 shows a map of the island with tidal wind and solar marked.

The limited lifespan of the underwater power cable connecting Rouque to the main utility is the impetus for migrating the island community to a self-sustaining grid. An extended timeline allows an incremental approach to be taken. First, energy conservation and efficiency measures reduced overall electricity demand. Second, circuit level energy monitoring equipment was used to identify high demand sources such as a broken well pump. Attention to these loads further reduced island wide demand. Third, investment in sources of renewable energy to offset electricity demand provided $4.2 \mathrm{~kW}$-installed capacity

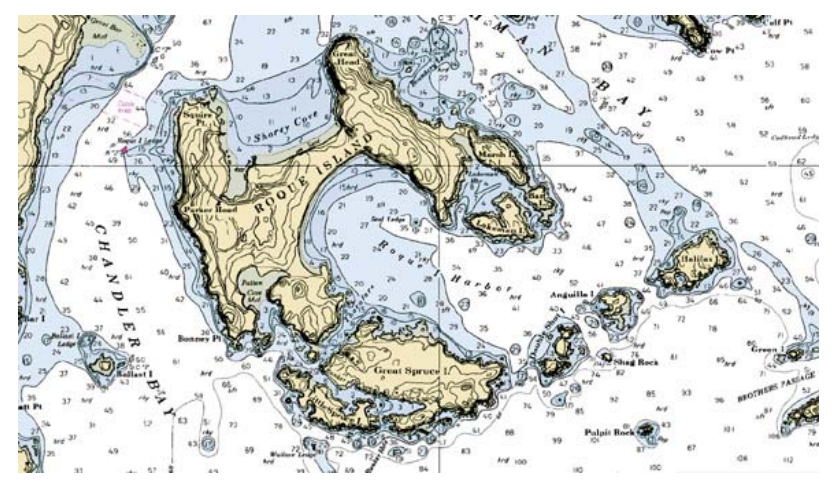

Figure 1. Map of rouqe island. 
of initial solar generation. An added $5.8 \mathrm{~kW}$ installed capacity is scheduled for September 2013. Additionally a wind power assessment concluded that a $10 \mathrm{~kW}$ system would be both economically and logistically feasible. Finally mechanisms to remotely and dynamically control a finite number of loads were installed.

These initial steps were used as a basis for design of the most efficient smart grid possible.

Subsequent steps of the work are detailed in this paper and include sizing the minimum tidal generation needed and comparing that need against the available resources as well as implementing control mechanisms for load balancing. Both efforts further reducing the required battery storage.

\section{System Design}

The smart grid system is comprised of renewable energy supply, battery storage, a smart controller, DDR, and a grid tie connection as shown in Figure 2. The smart controller monitors demand and renewable power production then dynamically increases and decreases demand via a select number of dispatchable loads and battery storage. The main utility grid provides and absorbs energy when necessary until $100 \%$ renewable energy penetration can be achieved. Losses in the under water cable and low power resale rates are incentives to utilize all locally generated power as well as to limit purchasing power from the electric grid.

Aggregating solar and wind energy resources with small tidal power generation significantly improves and simplifies the smart micro grid. The remaining power fluctuations are sufficiently small to be buffered with a limited battery storage unit acting both as spinning reserves and excess absorption. Battery storage provides flexibility to a micro grid as it allows time shifting between generation and consumption [8]. As a result, DDR can operate on an extended time series, bypassing many of the signal correction and conditioning issues [9] that

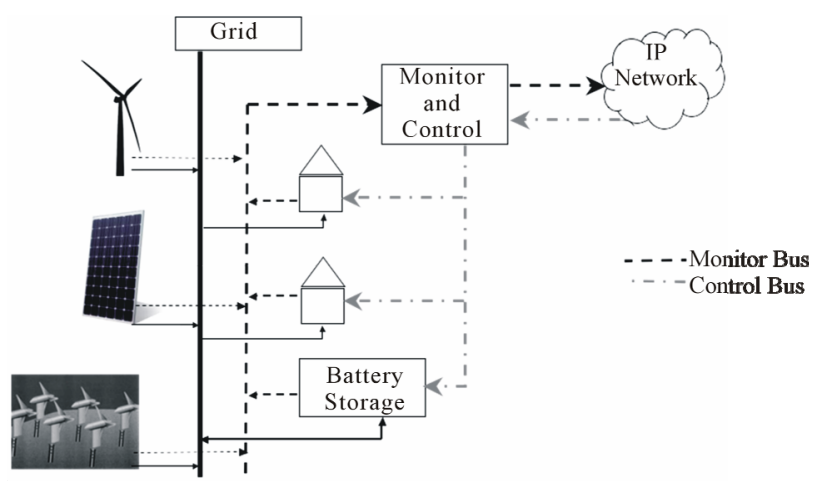

Figure 2. The Roque system is comprised of renewable energy supply, battery storage, a smart controller, load balancing capabilities, and a grid tie connection. accompany fast fluctuations of power caused by turning on and off loads.

The first order system analysis model is calculated using site-specific time series load and resource data. Circuit level power monitoring equipment (Savant Energy Monitor, Savant Systems LLC, Hyannis, MA) provides two years worth of high-resolution energy data for buildings on the island. Total island demand is monitored on a five second time scale and is $104 \mathrm{kWh}$ per day on average. Energy use on the island peaks from July through September, with a maximum monthly deviation in energy use across a year of $1800 \mathrm{kWh}$ on average.

The Roque micro-grid is designed with $10 \mathrm{~kW}$ installed capacity of both solar and wind power. Solar resource data are collected from an onsite small solar rooftop array (YL240P-29b, Yingli, China). Wind power data is calculated based on actual wind speed data from an anemometer at hub height located in close proximity to the proposed turbine site. The micro-grid design is based on distributed solar, wind and tidal generation systems aggregated for renewable energy penetration approaching one hundred percent.

The system is designed to limit battery storage to twelve 12-volt $100 \mathrm{AH}$ batteries providing 14,400-watt hours of storage or one eighth of the island daily energy consumption. A full day worth of battery storage would greatly reduce error and increase stability but the size, cost and logistics of transporting and maintaining that much storage is significant. The energy storage efficiency with the inverter is $90 \%$. A battery charge controller is used to efficiently charge batteries and control fluctuations in power draw and charging cycles. The system is configured such that the battery is charged exclusively by renewable energy sources at no greater than the maximum charge rate. The state of charge (SOC) is instrumental to the smart controller in determining load balancing.

\section{Tidal}

The first objective of this work is to quantify the tidal power generation for a non-autonomous Roque Island micro-grid. The results of this investigation will determine if the proposed tidal site on the northeast side of the island is sufficient to make investment worthwhile. A tidal resource estimate was determined by weighing average monthly energy demand with proposed solar and wind generation. Analysis is absent of supply from the main utility grid as a further objective is to minimize that input.

Variability in demand and solar and wind power supply create variations in net power in both directions. Analyzing net energy on a seasonal time scale, power generation from solar and wind equate to a significant portion of demand as shown in Figure 3. 


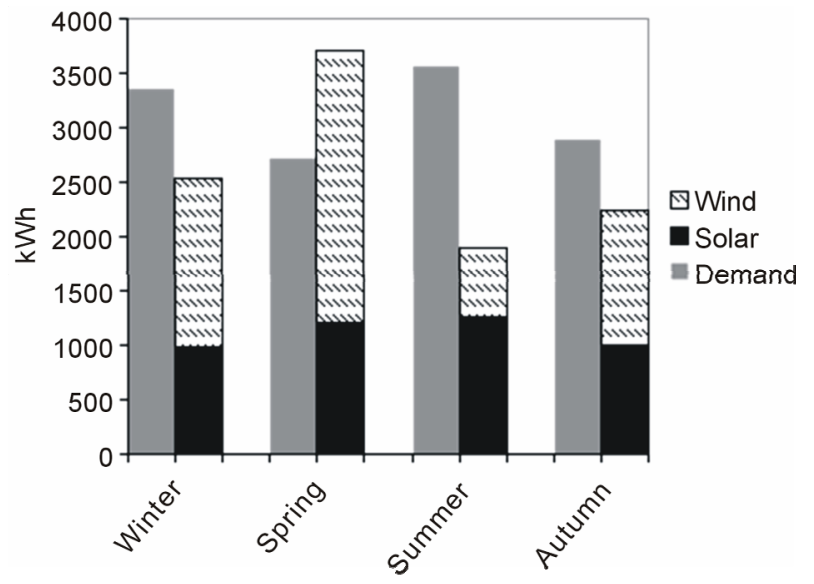

Figure 3. The monthly demand is not significantly greater than the supply of wind and solar but the timing of renewables is inconsistent.

Maximum net energy demand (demand minus supply) is $46.8 \%$ while minimum is $-36 \%$, indicating an excess of power. Monthly averages for high solar and wind penetration grids are insufficient for managing resources absent of significant energy storage due to intermittency in the supply. Day resolution of supply and demand more accurately reflects the requirements of grid management. Figure 4 shows daily net energy fluctuations from +127 $\mathrm{kWh}$ to $-58 \mathrm{kWh}$ for the example month of January 2012 , a typical month.

The net difference between average energy demand and energy production from solar and wind results in a median offset from zero of $34.6 \mathrm{kWh}$ as shown in Figure 5. Given a capacity factor of $30 \%$ [10] this translates to a $125 \mathrm{~kW}$ peak capacity tidal installation. A tidal resource generation of this magnitude would center the demandsupply variability at the optimum match point and move the demand side management requirements towards the load balancing capacity of the system.

Initial rough estimates indicate that a $5 \mathrm{~kW}$ system is significantly smaller than is feasible for tidal power generation on the northwest side of the island. The proposed site is $1600 \mathrm{M}$ across, has an average depth of 40' and a maximum flow of 2 knots. Tidal generators achieve power densities of approximately $8 \mathrm{~W} / \mathrm{m}^{2}$ at flow speeds of 2 knots [11]. This corresponds to a tidal generation resource of $0.33 \mathrm{MW}$. This resource is comparable to a similar site in Kennebec, Maine, which as about same depth and current speeds. That Kennebec site was analyzed as part of a North American tidal in-stream energy conversion feasibility study and found using very conservative assumptions to have a resource base of $0.4 \mathrm{MW}$ [12].

\section{Simulation Model}

A simulation of a smart grid for Roque Island was con-

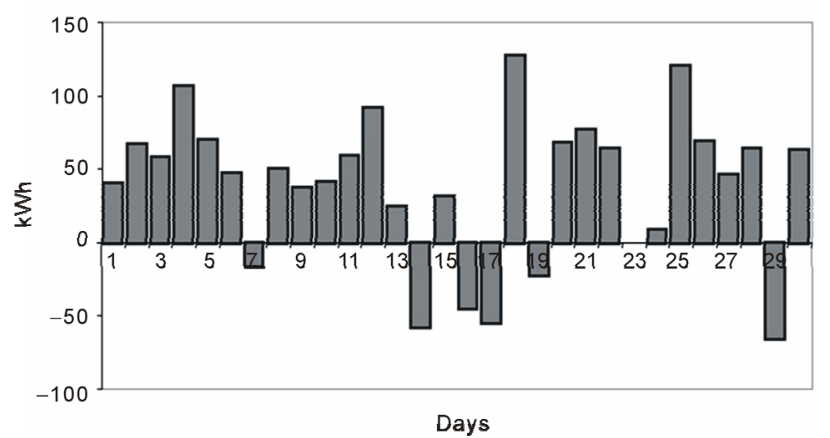

Figure 4. Daily net energy fluctuations for January, a typical month, vary from a maximum of $127 \mathrm{kWh}$ of unmet load to $58 \mathrm{kWh}$ of excess renewable energy supply.

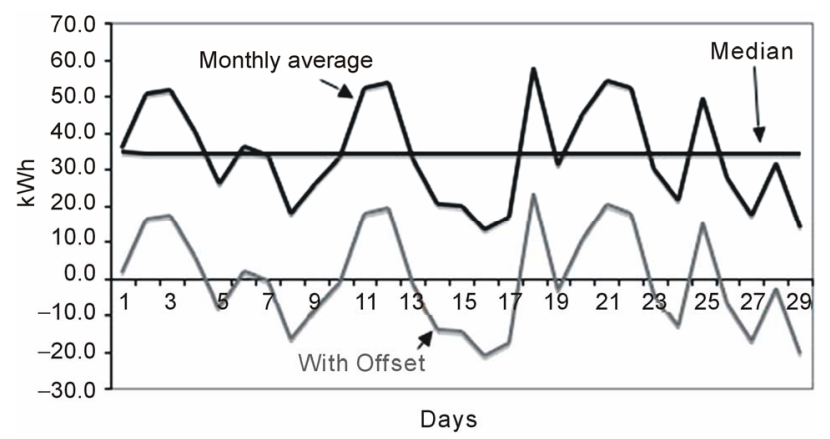

Figure 5. Average monthly net energy without tidal has a median offset from zero of $36.4 \mathrm{kWh}$. A tidal resource of that size reduces the size of battery storage needed.

structed using Simulink (version 8.0, Mathworks, Natick MA). The model block diagram is shown in Figure 6. The model focuses on the largest seasonal supply-demand mismatch periods. Power generation from wind, solar and tidal systems is compared with island electricity demand, to predict the net surplus or shortfall of renewable energy generation. That output interfaces with battery storage and adjustable load balancing capacity to ultimately provide the amount of excess power or shortfall in power that will be sent to or taken from the electric grid. This information will establish a baseline for the system that can be further improved through increased load management, conservation measures, or adjustments in battery storage and renewable energy supply. For example, pumped water storage, as a means of absorbing excess power, is advantageous given that water pumping is a significant demand on the system.

The system controller is fed high resolution current, voltage, power, power factor and direction data for every load and resource in the system including solar, tidal, wind, battery, grid connection and circuit level energy consumption. The controls are sufficient for extended time series DDR, which will further reduce peaks and troughs. SOC and charge rate are utilized for activation decisions by the smart controller. Loads for DDR are configured for on/off triggers and minimum duration be- 
tween power cycles. For example a chest freezer may be set to turn on if the internal temperature is greater than $T_{x}$ and turn off if it is less than $\mathrm{T}_{\mathrm{y}}$ with a minimum hold time of $\mathrm{Z}$ minutes. The large thermal mass of a freezer, infrequent opening and storing of food and large energy usage makes these freezers a useful DDR load. Additional demand side management can come from pumping water to the central cistern only during peak generation times.
The system employs a proportional integral (PI) controller scheme based on the battery SOC and charge rate to determine optimum demand reductions necessary to meet unrealized supply and maintain battery storage levels. Similarly, the system gradually increases demand to capture any surplus of supply for the distributed generators. Loads are dynamically brought on or off line based on a gradual approach to the set point. Figure 7 illustrates a flow chart for the controller. Demand not matched

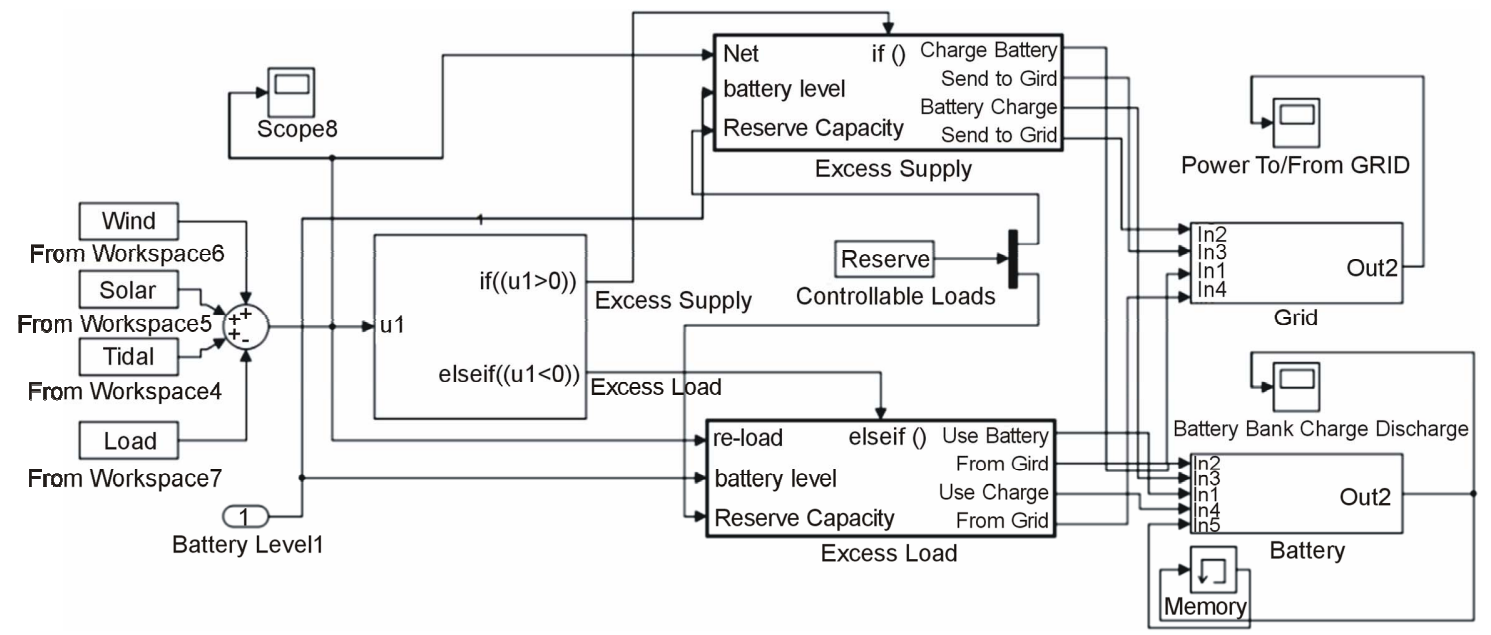

Figure 6. Simulink model for Roque smart grid: power generation from wind, solar and tidal systems is compared with island electricity demand, to predict the net surplus or shortfall of renewable energy generation.

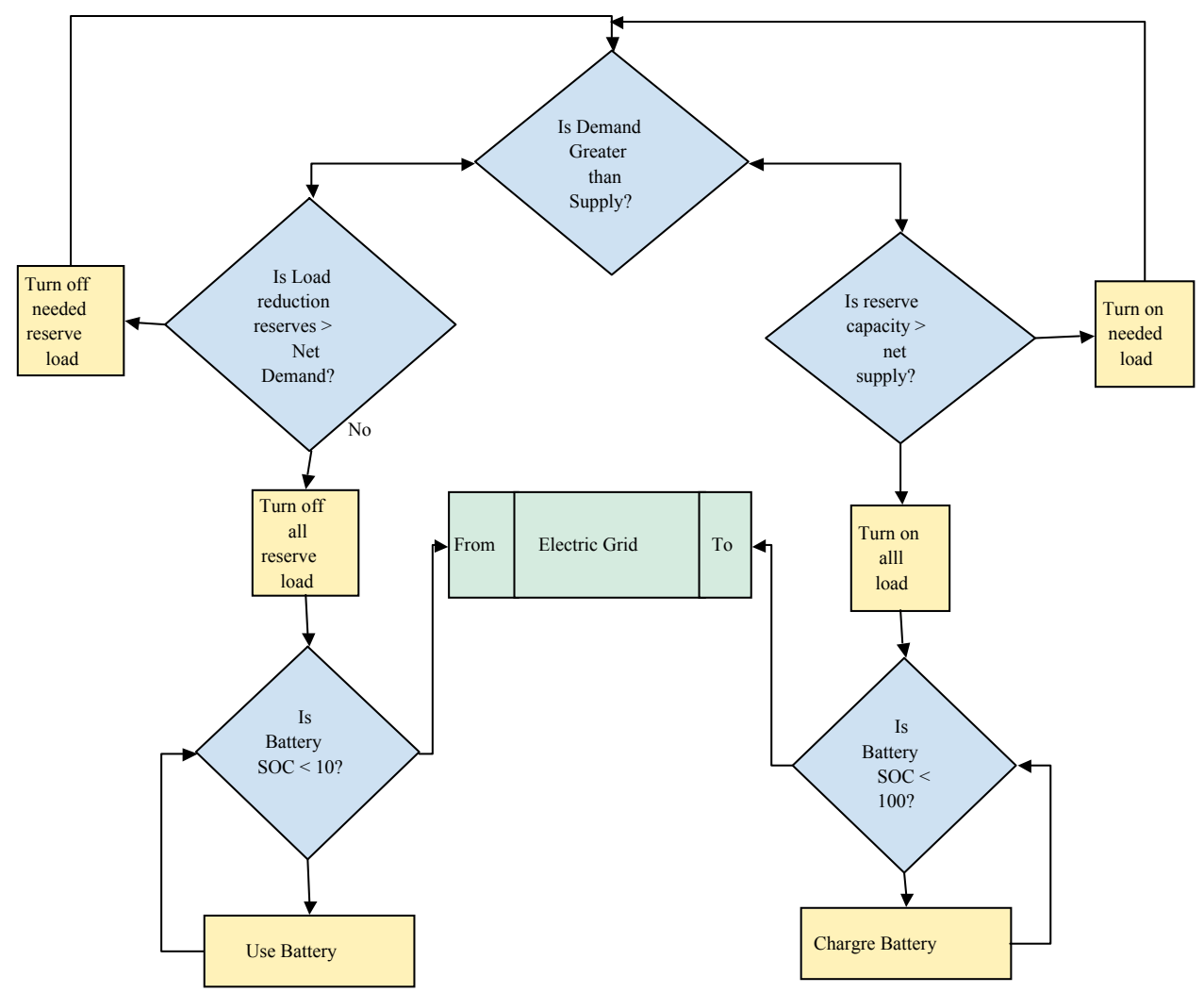

Figure 7. Smart controller flow chart. 
by load balancing capacity or provided by the battery storage unit is drawn from the grid. Likewise, excess supply, with maximum demand and maximum battery SOC, is absorbed by the grid. This design allows for slower transitions between charging and discharging phases using the battery storage as the system damper. The smart controller continuously monitors the magnitude and direction of power at the utility grid penetration point. The system attempts to offset any power through DDR and battery storage.

\section{Simulation Results}

By fixing all but one input of the system, the smart grid simulation is used to determine the amount of power sent to and from the electric grid as well as the charge and discharge cycles of the battery based on the variation of a single input. In this manner, multiple scenarios can be tested prior to deployment of renewable energy generation. Two sets of simulations were done for this work. First the size of the tidal generation was varied while all other inputs were fixed. Next, the optimum tidal generator size of those simulated was fixed into the model while the size of the load balancing capacity for dynamic demand response of loads was varied.

\subsection{Tidal}

Several tidal turbine sizes were simulated for the micro grid. Smaller generators are modeled for lower cut-in speeds producing a lower power output over longer portion of the tidal flow period, while larger turbines are modeled for higher cut-in speeds, resulting in a higher power output but for a shorter portion of a tidal cycle. The simulations are run with a one-hour time scale then summed per day for a three-month period. Inputs to the system include battery storage capacity of $14.4 \mathrm{kWh}$, solar and wind generation each with an installed capacity of $10 \mathrm{~kW}$ and the initial anticipated hourly load capacity for the island, $2000 \mathrm{~W}$ of hourly load balancing capacity. Table 1 summarizes the percent of excess generation and unmet load for these tidal turbines.

Table 1. \% grid interaction based on tidal generator.

\begin{tabular}{cccc}
\hline Tidal size & $\begin{array}{c}\text { Power generation } \\
\text { per cycle }\end{array}$ & $\begin{array}{c}\text { \% renewable } \\
\text { energy to grid }\end{array}$ & $\begin{array}{c}\text { \% load covered } \\
\text { by electric grid }\end{array}$ \\
\hline 0 & 0 & 0 & 11.6 \\
$4 \mathrm{~kW}$ & $65 \%$ & 3.3 & 3.2 \\
$6 \mathrm{~kW}$ & $65 \%$ & 6.5 & 1.3 \\
$10 \mathrm{~kW}$ & $65 \%$ & 13.9 & 0.3 \\
$12 \mathrm{~kW}$ & $65 \%$ & 18.6 & 0.1 \\
$30 \mathrm{~kW}$ & $25 \%$ & 64.3 & 0.0 \\
$64 \mathrm{~kW}$ & $25 \%$ & 81.0 & 0.0 \\
\hline
\end{tabular}

Without tidal power generation to augment solar and wind power generation, a relatively large amount of power is needed from the grid. Such a scenario would require more than doubling the battery capacity in the system in order to keep the grid interaction below $5 \%$. As a baseline, Figure 8 shows the power drawn from the electric grid when the island renewable energy portfolio is absent of tidal power. For this scenario a maximum of $11.6 \%$ of power is taken from the grid to make up for shortfalls in production.

Table 1 shows that the $4 \mathrm{~kW}$ tidal generator provides the lowest grid interaction. The daily grid interactions for this turbine and the $30 \mathrm{~kW}$ turbine are graphed in Figure 9. Positive values represent power taken from the grid while negative values indicate power sent to the grid.

The $4 \mathrm{~kW}$ tidal generator requires that the micro grid only take $3.3 \%$ of its power from the electric grid and send $3.2 \%$ of the total renewable energy generation back to the grid. The $30 \mathrm{~kW}$ tidal generator eliminates grid dependence but increases the amount of renewable energy generation sent back to the electric grid to $64 \%$. This excess power could be potential income for an island with a suitable underwater cable. However, given the cost of tidal energy and transmission losses it is unlikely that the system would justify the additional capital investment. The objective for Roque is to move to war eliminating the cable rather than replacing it, which would be required with this larger tidal generator.

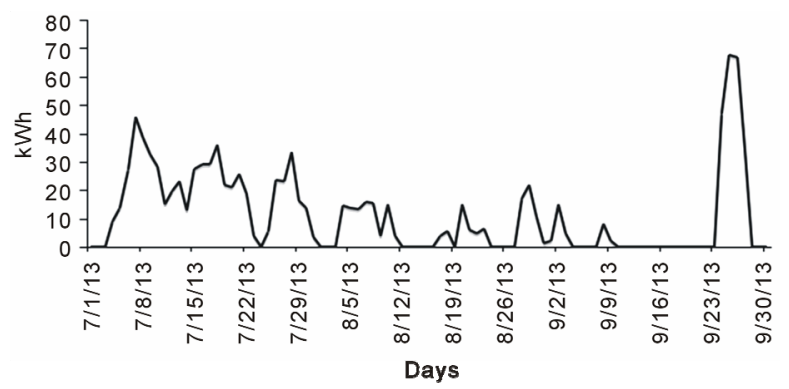

Figure 8. Absent of tidal power the micro grid requires $11.6 \%$ of power to come from the main electric grid.

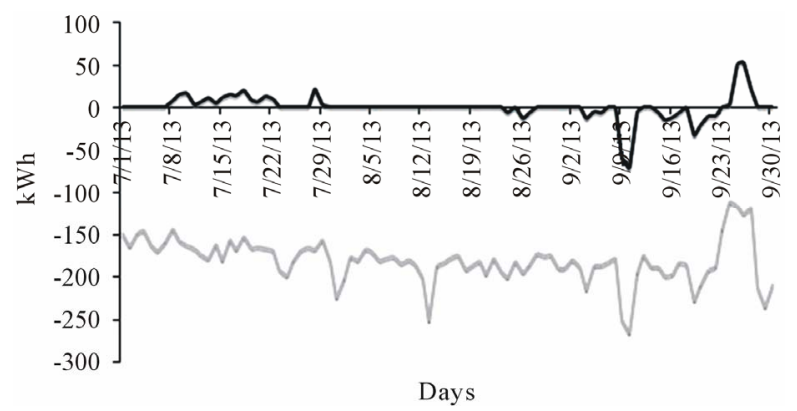

Figure 9. Power interactions with the main electric grid for a $4 \mathrm{~kW}$ turbine (black) and $30 \mathrm{~kW}$ turbine (grey): positive values indicate power taken from the electric grid while negative values show power sent to the electric grid. 


\subsection{Dynamic Demand Response}

Since the $4 \mathrm{~kW}$ tidal generator that provides a modest power output over a longer time provides the lowest grid interaction for the given micro grid configuration, this choice is fixed for the dynamic demand response modeling to determine the optimum load balancing capacity.

As a baseline, a simulation was run for power interactions with the grid absent of load balancing. These results are shown in Figure 10. A maximum of $12.3 \%$ of power is taken from the grid to make up for shortfalls in production while $2.6 \%$ of renewable energy generation is sent back to the grid for the same seasonal period. Hourly power fluctuations to and from the grid peak just over $6000 \mathrm{~W}$, which is consistent with the predicted net surplus based on demand, generation sources and battery capacity.

Initial estimates for hourly load balancing capacity for the island is $2000 \mathrm{~W}$. Simulations were run for $2000 \mathrm{~W}$ and 3000 W. The results are shown in Figure 11.

Simulation using the hourly load balancing capacity for the island of $2000 \mathrm{~W}$ requires the micro grid to take $3.2 \%$ of its power from the electric grid and send $3.3 \%$ of the total renewable energy generation back to the grid. An increase of load balancing capacity to $3000 \mathrm{~W}$ reduces the power needed from the electric grid to $0.6 \%$ and

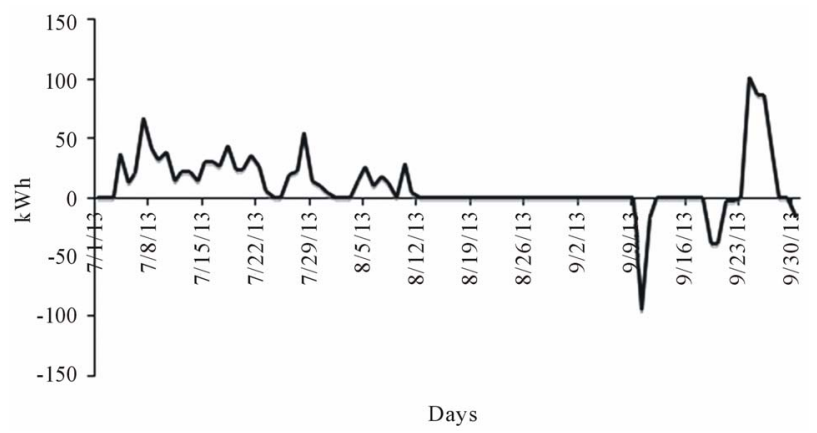

Figure 10. Power interactions with the grid absent of load balancing results in a maximum of $12.3 \%$ power taken from the grid while $2.6 \%$ of renewable energy generation is sent back to the grid.

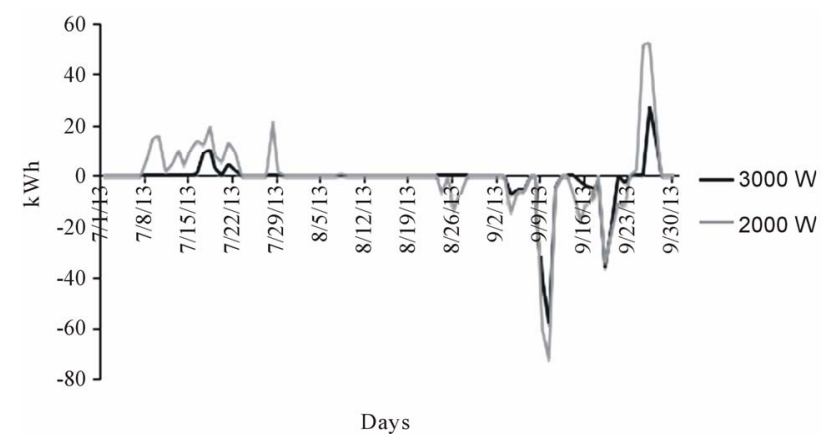

Figure 11. Power interactions with the electric grid for hourly load balancing capacities of $2000 \mathrm{~W}$ and $3000 \mathrm{~W}$. the power sent to the grid to $2.5 \%$. These results along with no load balancing are listed in Table 2.

Dynamic demand response will alter load patterns as heating and cooling is bundled around high supply time periods. Combined with the freezers and water pumping the high percentage of dynamic demand response is realistic for this system. Monitoring of the interface point for the main electric grid will provide real power consumption and direction data with a five minute resolution. This monitoring data, fed back into the simulation model to analyze shifts in system power peaks and individual loads, will assist in optimizing load balancing capacity and incrementally reduce the time scale for load manipulation.

\section{Conclusion}

Renewable energy driven micro-grids that can include a tidal power generator of modest size can greatly improve the stability of the grid. If a reasonable portion of the load is interruptible and centrally controlled, the aggregation of intermittent renewable resources of solar and wind with a predictable renewable generator can provide the basis for an independent stable grid. The Roque Island grid is a living laboratory where demand has been managed with passive monitoring of energy usage on the island [13]. After first reducing demand, performance of small-scale mature renewable technologies like photovoltaics has been evaluated. Controlling the island demand by interrupting loads is operational. The goal of a nearly independent $100 \%$ renewable micro-grid now appears to be possible based on models, which include small input from a reliable renewable energy source, tidal energy.

The model results support further investment in the evaluation of the tidal resource by installing flow meters and initiating cost assessment. While tidal energy is a relatively immature technology [14], it is clear that a relatively small tidal resource can have a significant impact on grid stability.

The portion of the load, which must be centrally controlled to minimize interaction with the utility grid, is relatively large even for this small grid with comparatively large interruptible loads. The scalability of the results is not clear for applications where interruptible loads such as pumping water to a cistern or cooling large freezers is a smaller portion of energy usage. However when con-

Table 2. \% grid interaction based on load balancing capacity.

\begin{tabular}{ccc}
\hline Load balancing & $\begin{array}{c}\text { \% power taken } \\
\text { from the grid }\end{array}$ & $\begin{array}{c}\text { \% renewable energy } \\
\text { to grid }\end{array}$ \\
\hline 0 & $12.3 \%$ & $2.6 \%$ \\
$2000 \mathrm{~W}$ & $3.2 \%$ & $3.3 \%$ \\
$3000 \mathrm{~W}$ & $0.6 \%$ & $2.5 \%$ \\
\hline
\end{tabular}


sidered on a community scale including heating, cooling, water treatment and other capital intensive energy usage may make a sufficiently large portion of the load interruptible. Regardless of the scale of the general applicability of the approach, the combination of more stable renewable energy sources and demand control has the potential to stabilize outlying portions of the grid with high cost to serve. For Roque Island, the benefits are immediate with a reduction in loss over the connecting cable for both purchased and excess power resulting in power cost reductions.

Scaling this work for mainland communities allows community scale smart-grids with high renewable energy penetration to utilize the electric grid as backup storage. This would be an opportunity for green communities to continue experiment with grid related concepts while having a positive impact on the community through exploration of economically promising technologies. Accessibility to small scale tidal generation or river hydro-electric resources for these communities will greatly improve the stability of their micro-grid, reduce non-renewable energy usage and increase overall grid stability. While extensive modeling would be required to determine if the impact is significant, it may even be possible to pair renewable energy sources in this manner with certain types of customers in order to impact overall grid stability for high renewable penetration grids.

\section{Acknowledgements}

The Maine Space Grant Consortium provided funding for the Roque micro grid research via their Two-Year Research and Higher Education Program. Roque manager, Bruce Patterson, and his entire staff were generous and hospitable in providing us access to the island. The support of the board of trustees for this research is greatly appreciated. Over the course of these projects we have benefited from discussion, advice, and support from: Randy Goodhue, Dave Feldman, Sig Eschholz, Michael Shook and Robert Parker.

\section{REFERENCES}

[1] S. Solomon, D. Oun, M. Manning, M. Chen, M. Marquee and Intergovernmental Panel on Climate Change, "Climate Change 2007: The Physical Science Basis. Contribution of Working Group I to the Fourth Assessment," Report of the Intergovernmental Panel on Climate Change, Cambridge University Press, Cambridge, 2007.
[2] G. M. Shafiullah, A. M. Oo, A. S. Ali and P. Wolfs, "Smart Grid for a Sustainable Future," 2013.

[3] E. Hart, E. Stoutenburg and M. Jacobson, "The Potential of Intermittent Renewables to Meet Electric Power Demand: Current Methods and Emerging Analytical Techniques," Proceedings of the IEEE, Vol. 100, No. 2, 2012, pp. 322-334. http://dx.doi.org/10.1109/JPROC.2011.2144951

[4] D. Holmberg, "Demand Response and Standards," BACnet ${ }^{\circledR}$ Today \& the Smart Grid-A Supplement to Ashrae Journal, November 2011, pp. 823-828.

[5] A. Scaglia, C. Brocca, G. Torri and VialeSarca, "A Model for the Design and Development of Smart Micro Grids," 21 WEC World Energy Congress di Montréal in Canada, 2010.

[6] E. Hart, E. Stoutenburg and M. Jacobson, "The Potential of Intermittent Renewables to Meet Electric Power Demand: Current Methods and Emerging Analytical Techniques," Proceedings of the IEEE, Vol. 100, No. 2, 2012, pp. 322-334. http://dx.doi.org/10.1109/JPROC.2011.2144951

[7] Ocean Energy Council, “Tidal Energy,” 2012. http://www.oceanenergycouncil.com/index.php/Tidal-Ene rgy/Tidal-Energy.html

[8] R. Lassester, "Microgrids and Distributed Generation," Journal of Energy Engineering, American Society of Civil Engineers, Vol. 133, No. 3, 2007, pp. 144-149. http://dx.doi.org/10.1061/(ASCE)0733-9402(2007)133:3( 144)

[9] Y. Yin, X. Luo, S. Guo, Z. Zhou and J. Wang, “A Battery Charging Control Strategy for Renewable Energy Generation Systems," IAENG Proceedings of the World Congress on Engineering, Vol. 1, 2008, pp. 2-4.

[10] M. Palodichuk, B. Polagye and J. Thomson, "Resource Mapping at Tidal Energy Sites," 2013.

[11] D. MacKay and D. Cambridge, "United Kingdom: UIT," 2009. www.withouthotair.com/

[12] G. Hagerman, B. Polagye, R. Bedard and M. Previsic, "Methodology for Estimating Tidal Current Energy Resources and Power Production by Tidal In-stream Energy Conversion (TISEC) Devices. EPRI North American Tidal in Stream Power Feasibility Demonstration Project," 2006.

[13] A. Demeo and M. Peterson, "Island Community Smart Grid Utilizing Dynamic Demand Response and Tidal Power for Grid Stabilization. Smart Grid and Renewable Energy," 2013.

[14] C. M. Johnstone, D. Pratt, J. A. Clarke and A. D. Grant, "A Techno-Economic Analysis of Tidal Energy Technology Original Research Article Renewable Energy," Vol. 49, 2013, pp. 101-106. 